\title{
Preconditioning with mono and polyunsaturated fatty acids and low-intensity electrical stimulation. Effects on skin repair in rats ${ }^{1}$
}

\author{
Maria dos Prazeres Carneiro CardosoI, Andréa de Oliveira Albuquerque ${ }^{\mathrm{II}}$, Virginia Claudia Carneiro Girão ${ }^{\mathrm{III}}$, Margarida Maria \\ de Lima Pompeu ${ }^{\mathrm{IV}}$, Cícero Igor Simões Moura Silva ${ }^{\mathrm{V}}$, Orleâncio Gomes Ritardo de Azevedo ${ }^{\mathrm{VI}}$, Sergio Botelho Guimarães ${ }^{\mathrm{VII}}$, \\ Paulo Roberto Leitão de Vasconcelos ${ }^{\text {III }}$
}

DOI: http://dx.doi.org/10.1590/S0102-86502015002000004

IFellow Master degree, Postgraduate Program in Surgery, Department of Surgery, UFC, Ceara, Brazil. Conception of the study, technical procedures, acquisition of data.

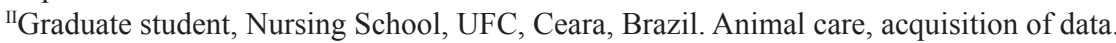

IIIAssociate Professor, Department of Morphology, Faculty of Medicine, UFC, Ceara, Brazil. Histopathological analysis.

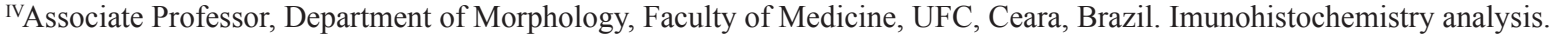

${ }^{\mathrm{v}} \mathrm{PhD}$, Department of Surgery, Faculty of Medicine, UFC, Ceara, Brazil. Analysis and interpretation of data.

${ }^{\mathrm{VI}} \mathrm{PhD}$, Laboratory of Ontogeny and Nutrition of Tissue Healing, Institute of Biomedicine of the Brazilian Semi Arid, UFC, Ceara, Brazil. Drafting of the manuscript.

VIIPhD, Associate Professor, Department of Surgery. Head, Surgical Research Laboratory (LABCEX), UFC, Ceara, Brazil. Manuscript writing, critical revision.

VIIIPhD, Full Professor, Department of Surgery. Coordinator, Postgraduate Program in Surgery, UFC, Ceara, Brazil. Conception, design, intellectual and scientific content of the study, critical revision, final approval of manuscript.

\section{ABSTRACT}

PURPOSE: To evaluate the effects of preconditioning with oils mixes containing $\omega 3 / \omega 6 / \omega 9$ associated with micro-currents on skin repair in rats.

METHODS: One-hundred and eight Wistar rats randomized into G-1, G-2 and G-3 groups were treated with saline (0.9\%), mix 1 (corn+soybean oils) and mix 2 (olive+canola+flaxseed oils), respectively, in a single dose $(0.01 \mathrm{ml} / \mathrm{g})$ by gavage. Next, each group was subdivided into sham and stimulated subgroups. Pulsed-wave microcurrents $(0.5 \mu \mathrm{A}, 0.5 \mathrm{~Hz})$ were applied to stimulated subgroups for $20 \mathrm{~min}$. One hour later anesthetized rats were subjected to surgery. A dorsal incision (6 cm long) was carried out and closed with interrupted nylon sutures. Samples $\left(1 \mathrm{~cm}^{2}\right)$ were harvested from the mid-portion of the incision on the 7, 14, 21 post-operative (P.O.) days. Variables were analyzed using Mann-Whitney/Dunn tests Significance level was set to $5 \%(\mathrm{p}<0.05)$.

RESULTS: Micro-currents promoted increase of exudate and reduction of epithelialization on day 7 in G1 rats. Mixes $1 / 2$ reduced vascularization on 7/14th days P.O. Both 1/2 mixes reduced fibrosis on day 14. Preconditioning with mix 1 led to increased expression of NF-kB on the 7 th day.

CONCLUSION: Preconditioning with microcurrents has pro-inflammatory effects while oil mixes 1 and 2 decrease fibrosis and vascularization in the proliferative phase of cicatrization.

Key words : Oils. Electric Stimulation Therapy. Wound Healing. Skin. Rats. 


\section{Introduction}

Wound healing is a complex process that involves a series of biochemical and cellular reactions and. occurs as a sequence of events, which includes inflammation, proliferation, and migration of different cell types ${ }^{1}$. After forty-eight hours the inflammatory infiltrate consisting of monocytes is predominantly due to the short lifetime of neutrophils. Leukocytes play phagocytosis on the aggressors, promoting the death of microorganisms, leading to the release of products to the extracellular medium, increasing the initial inflammatory effect ${ }^{2}$.

Vascular changes consist of a cascade of activated and controlled chemical mediators reactions. These mediators act on the microcirculation, leading to increased vascular permeability and can be classified by mediators of fast-transient action and long-acting mediators ${ }^{2}$. Nuclear factor kappa-light-chain-enhancer of activated B cells (NF-kB) is a nuclear transcription factor that is activated by lipopolysaccharide agents and has the ability to bind to a sequence of 10 base pairs of the promoter region of the gene encoding the light chain of the molecules of KB cells ${ }^{3}$. Regardless of the stimulus, there may be involvement of reactive oxygen species and increased intracellular calcium for activation of NF-kB. When not stimulated NF-kB is found in the cytoplasm, bound to an inhibitory protein, IKB; this complex prevents the translocation of NF-kB to the nucleus. Thus, phosphorylation and degradation of $\mathrm{IkB}$ are required for translocation ${ }^{4}$.

Heat shock response is one of the protective mechanisms evolutionarily acquired and is promoted by heat shock proteins (HSP), which retain their intact structures under such conditions, assisting in the maintenance and proper formation of proteins ${ }^{5}$. HSP-27 is a heat shock protein with low molecular weight that interact with polyunsaturated fatty acids. These proteins have molecular weights between 18 and $30 \mathrm{kDa}$ and are called small HSPs (small HSP). Its constitutive expression can be found in the nucleus and in the cytoplasm and are functionally involved in preventing denaturation of proteins and protection against cell injury and death ${ }^{6}$.

Peroxynitrite anion (ONOO-), the product of the reaction between superoxide anion $\left(\mathrm{O}_{2}^{-{ }^{-}}\right)$and nitric oxide $(\cdot \mathrm{NO})$ and its conjugated acid, peroxynitrous acid $(\mathrm{ONOOH})$, are potent oxidants known to be formed in vivo ${ }^{7}$. Peroxynitrite can enhance inflammatory mediator pathways ${ }^{8}$. Nitrotyrosine in another component that participates in the nitration process involving radical mechanisms in which a derivative of the electron peroxynitrite attacks the aromatic ring of tyrosine, leading to formation of tyrosyl radical, which rapidly combines with nitrogen dioxide $\left(\mathrm{NO}_{2}\right)$ equivalents to form 3-nitrotyrosine ${ }^{9}$.

The use of electrical stimulation in the injured tissue aims to accelerate the healing process. Clinical studies have shown that electrical stimulation induces an increase in a (ATP) concentration in tissues, increased protein synthesis, migration of epithelial cells and fibroblasts in the region of the injury, reduction of the edema and inhibition of the growth of some pathogens 9 .

There are three families of unsaturated fatty acids (PUFA) omega-3 $\alpha$-linolenic acid ( $\omega-3)$, omega-6 linoleic acid $(\omega-6)$ and omega-9 oleic acid ( $\omega-9)$, The $\alpha$-linolenic fatty acid (ALA, 18:3 $n-3)$ is the precursor of eicosapentaenoic acid (EPA, 20:5 n- 3), docosapentanóico (DPA, 22:5 n- 3), docosahexaenoic (DHA ; 22: $6 n-3)$ and linoleic acid (LA, 18:2 n-6), a precursor of arachidonic acid (AA, 20:4 n -6). Both ALA and LA can not be synthesized by the human body and interconverted ${ }^{10-11}$.

\section{Methods}

Approval for experimental use of laboratory animals was obtained from the local Ethics Committee on Animal Use (CEPA), protocol \#105/09, May 2012. All surgical procedures and animal handling were conducted in accordance with the Brazilian Federal Law No. 11794 of October 8, 2008 (http://www.planalto.gov.br/ ccivil_03/_Ato2007-2010/2008/Lei/L11794.htm).

One hundred and eight male Wistar rats (270-350g) provided by the Central Animal Vivarium of the Federal University of Ceara were randomized into three groups $(n=36)$ for the experiments (Table 1). All animals were housed in polypropylene cages at ambient temperature of $24^{\circ} \mathrm{C}$ on a $12 \mathrm{~h}$ light-dark cycle. Rats were allowed free access to food (Purina chow) and fasted $12 \mathrm{~h}$ before the experimental procedure. Tap water was offered $\mathrm{ad}$ libitum until the beginning of the experiment. 
TABLE 1 - Groups, number of animals, treatments and procedures.

\begin{tabular}{|c|c|c|c|c|}
\hline Groups & Sub-groups & $n$ & Treatments & Electric stimulation \\
\hline \multirow[b]{2}{*}{$\begin{array}{l}\mathrm{G} 1 \\
\mathrm{n}=36\end{array}$} & NS & 18 & \multirow{2}{*}{$\begin{array}{c}\text { saline } 0.9 \% \text {, single dose } \\
0.01 \mathrm{ml} / \mathrm{g} \text { by gavage }\end{array}$} & none \\
\hline & ST & 18 & & $\begin{array}{l}\text { Pulsed-wave microcurrents } \\
(0.5 \mu \mathrm{A}, 0.5 \mathrm{~Hz}) \text {, for } 20 \mathrm{~min} \\
\quad \text { (single application) }\end{array}$ \\
\hline \multirow[b]{2}{*}{$\begin{array}{l}\mathrm{G} 2 \\
\mathrm{n}=36\end{array}$} & NS & 18 & \multirow{2}{*}{$\begin{array}{c}\text { corn }+ \text { soybean oils } \\
{[\omega-6+\omega--9], \text { single dose }} \\
0.01 \mathrm{ml} / \mathrm{g}) \text { by gavage }\end{array}$} & none \\
\hline & ST & 18 & & $\begin{array}{l}\text { Pulsed-wave microcurrents } \\
(0.5 \mu \mathrm{A}, 0.5 \mathrm{~Hz}) \text {, for } 20 \mathrm{~min} \\
\text { (single application) }\end{array}$ \\
\hline & NS & 18 & olive + canola + flaxseed oils & none \\
\hline $\begin{array}{l}\mathrm{G} 3 \\
\mathrm{n}=36\end{array}$ & $S T$ & 18 & $\begin{array}{l}{[\omega-3+\omega-6+\omega--9), \text { single }} \\
\text { dose } 0.01 \mathrm{ml} / \mathrm{g}) \text { by gavage }\end{array}$ & $\begin{array}{l}\text { Pulsed-wave microcurrents } \\
(0.5 \mu \mathrm{A}, 0.5 \mathrm{~Hz}), \text { for } 20 \mathrm{~min} \\
\text { (single application) }\end{array}$ \\
\hline
\end{tabular}

$\mathbf{S T}=$ stimulated, $\mathbf{N S}=$ non-stimulated

Samples were collected from each subgroup on the 7th $(n=6), 14$ th $(n=6)$ and 21 st day $(n=6)$ of the experiment. After sample collection, the animals were killed by an overdose of anesthetics (ketamine $500 \mathrm{mg} / \mathrm{kg}+\mathrm{Xy}-$ lazine $250 \mathrm{mg} / \mathrm{kg}$ )

Oil mixes were purchased from NUTRIMED (Nutrição Enteral e Parenteral Ltda), Fortaleza-CE, Brazil. Antibodies markers for heat shock protein 27(HSP27) (MsAbto-4-hydroxy); nitrotirosyne (NT) (39B6 monoclonal) and transcription factor kappa b (NFkB) (Santa Cruz P50 SC-mouse mononuclear) were purchased from Imprint do Brazil (Campinas-SP).

\section{Surgical procedure}

Microcurrents were delivered by Stimulus Microcurrent Face ${ }^{\circledR}$ HTM (HTM-Electrical and Electronic Equipment Ltda, Sao Paulo, Brazil). The device generates amplified continuous and pulsed currents with two independent channel outputs, frequency $0.95 \mathrm{~mA} \pm 10 \%$, with inversion of polarity every 2.5 seconds. Selection of current intensity, frequency and duration of electric stimulation was based on previous publication ${ }^{12}$.

Anesthetized rats with ketamine hydrochloride (Dopolen $^{\circledR}$, Agribands Brazil Ltda) $90 \mathrm{mg} / \mathrm{Kg}+$ xylazine hydrochloride (Rompun ${ }^{\circledR}$, Bayer Animal Health) $10 \mathrm{mg} / \mathrm{Kg}$ intraperitoneally were positioned prone on a flat surface. A 6 $\mathrm{cm}$ long incision ${ }^{13}$ was performed, as depicted on Figure 1. The incision was deepened through the skin and panniculus carnosus to superficial muscle fascia. The starting point of the incision had an upper limit in the transverse line at the level of the inferior angle of the scapula. After seven, 14 and 21 days postoperatively, the animals were again anesthetized for removal of skin samples for laboratory and histological studies.

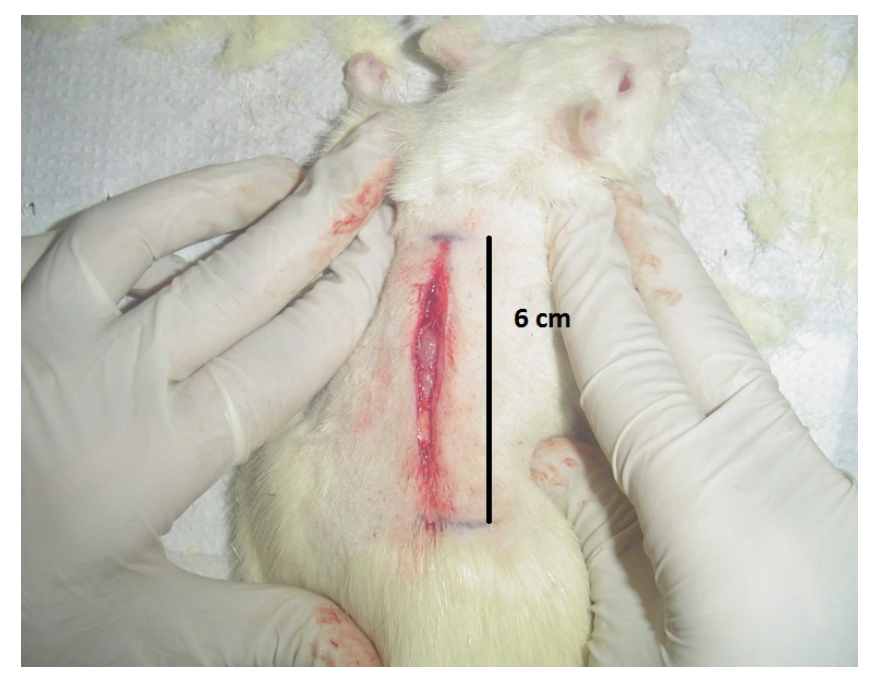

FIGURE 1 - Detail of the dorsal incision, extending from a line connecting the inferior border of the scapulae and down for $6 \mathrm{~cm}$ as originally described by Borba ${ }^{13}$.

\section{Histopathological analysis}

Tissue specimens ( skin fragments measuring $1 \mathrm{x} 1 \mathrm{~cm}$ ) were processed routinely for light microscopy (fixating, dehydrating, embedding, cutting, and staining with hematoxylin and eosin [HE]. The analysis of histological sections was performed by the same pathologist blinded to the identification of groups. The data was classified according to the intensity of the healing process ${ }^{14}$ and transformed into quantitative variables as follows: 
Exsudates: $0=$ normal intensity, $1=$ mild; $2=$ moderate and $3=$ intense

Epithelialization: $0=$ absent, $1=$ partial, $3=$ total

Fibrosis: $0=$ absent, $1=$ mild, $2=$ moderate, $3=$ intense

Vascularization: $\quad 0=$ absent,$\quad 1=$ mild,$\quad 2=$ moderate, $3=$ intense

\section{Immunohistochemistry analysis}

The immunohistochemical reactions (StreptavidinBiotin method) were performed at the laboratory of the Center for Studies in Microscopy Images and Procedures of the department of Morphology, Federal University of Ceara. Tissue sections were deparaffinized and rehydrated through xylene and graded alcohols after antigen retrieval. Endogenous peroxidase was blocked $(15 \mathrm{~min})$ with hydrogen peroxide and $3 \%$ in phosphate buffered and washed in saline (PBS). Quantitative analysis of samples of epithelial cells in the incision areas were carried out with an Olympus Optical microscope - model DX41 (Olympus Corporation, Tokyo, Japan) and a Digitimer Blood cell counter. (Digitimer Ltd, Hertfordshire, England).

\section{Statistical analysis}

Statistical analysis was performed using Graphpad Prism 5.0 (GraphPad Software, San Diego California USA, www.graphpad. com). After testing all data for distribution, ANOVA/Bonferroni, Kruskal-Wallis or Mann-Witney tests were used, as required. The significance level for rejecting the null hypothesis was $5 \%(p<0.05)$.

\section{Results}

\section{Effect of oil mixes (G2 and G3 groups) on exsudates and re-epithelialization of skin lesions in rats compared to negative control}

Groups G2 and G3 rats (non-stimulated rats, treated with oil mixes) presented no significant differences when comparing exudates and re-epithelialization variables with control groups, in timepoints 14 and 21 days. However there was a significant difference between rats on the 7 th day regarding both the exudates $(p<0.05)$ and the re-epithelialization $(p<0.01)$ (Table 2$)$.

TABLE 2 - Effect of oil mixes (G2 and G3 groups) on exudates and re-epithelialization of skin lesions in rats compared to negative controls.

\begin{tabular}{ccccccc}
\hline Time-point & \multicolumn{3}{c}{ EXUDATES } & \multicolumn{2}{c}{ RE-EPITHELIALIZATION } \\
\hline & $\mathrm{G} 1$ & $\mathrm{G} 2$ & $\mathrm{G} 3$ & $\mathrm{G} 1$ & $\mathrm{G} 2$ & $\mathrm{G} 3$ \\
$7^{\mathrm{TH}} \mathrm{DAY}$ & $2(1-2)$ & $1.5(1-2)^{*}$ & $2(1-3)^{*}$ & $2(1-2)$ & $2(1-2)^{* *}$ & $2(0-2)^{* *}$ \\
$14^{\mathrm{TH}} \mathrm{DAY}$ & $1.5(1-3)$ & $1(1-2)$ & $1(1-2)$ & $2(0-2)$ & $1(0-2)$ & $2(1-2)$ \\
$21^{\mathrm{TH}} \mathrm{DAY}$ & $1(1-2)$ & $1(1-1)$ & $1.5(1-3)$ & $2(2-2)$ & $1(0-2)$ & $1.5(0-2)$ \\
\hline
\end{tabular}

Group G1, Negative Control (Saline); Group G2, Neutral control ( $\omega-3+\omega-6+\omega-9)$; Group G3, test ( $\omega-6+\omega-9)$,. non-stimulated groups The data represent Median+range (minimum-maximum) of microscopic scores. Tissue samples were collected on $7^{\text {th }}, 14^{\text {th }}$ and $21^{\text {th }}$ days after injury. Kruskal-Wallis/Dunn tests. Differences of G2, G3 groups (time points 14 and 21 days) compared to G1 are not significant. Differences on exsudates and re-epithelializaiton was identified in G2 and, G3 rats (*p $>0.05, * * p<0,001$ compared with G1)

\author{
Effect of oil mixes (G2 and G3 groups) on fibrosis \\ and vascularization of skin lesions in rats compared \\ to negative control
}

Significant decrease in fibrosis and on day 14 in G2 and G3 and and in vascularization in G3 rats, compared with control was identified. Furthermore significant decreased vascularization on the 7 th post-operative day was observed in $\mathrm{G} 2$ rats compared to G1 (Table 3).

TABLE 3 - Effect of oil mixes (G2 and G3 groups) on fibrosis and vascularization of skin lesions of rats compared to negative control.

\begin{tabular}{lcccccc}
\hline Time-point & \multicolumn{3}{c}{ FIBROSIS } & \multicolumn{3}{c}{ VASCULARIZATION } \\
\hline & $\mathrm{G} 1$ & $\mathrm{G} 2$ & $\mathrm{G} 3$ & $\mathrm{G} 1$ & $\mathrm{G} 2$ & $\mathrm{G} 3$ \\
\cline { 2 - 7 } $7^{\mathrm{TH}} \mathrm{DAY}$ & $2(1-2)$ & $1(1-2)$ & $2(1-2)$ & $2(1-3)$ & $0.5(0-2) *$ & $2(1-3)$ \\
$14^{\mathrm{TH}}$ DAY & $2.5(1-3)$ & $1(1-1) *$ & $1(1-1) *$ & $2.5(1-3)$ & $1(0-2)$ & $0(0-2) *$ \\
$21^{\mathrm{TH}}$ DAY & $1.5(1-2)$ & $1(1-2)$ & $1(1-3)$ & $1(1-1)$ & $1(0-2)$ & $0(0-3)$ \\
\hline
\end{tabular}

Group G1, Negative Control (Saline);group G2, Neutral control ( $\omega-3+\omega-6+\omega-9)$; group G3, test ( $\omega-6+\omega-9)$,. non-stimulated groups. The data represent Median+range (minimum-maximum) of microscopic scores. Tissue samples were collected on $7^{\text {th }}, 14^{\text {th }}$ and $21^{\text {th }}$ days after injury. Kruskal-Wallis/Dunn tests. ${ }^{*} p<0.05$ compared to negative control 
Effect of oil mixes (G2 and G3 groups) on exsudates of skin lesions in rats compared to sham subgroups

Significant increase $(\mathrm{p}<0.05)$ on exudates on day 7 was identified when $\mathrm{G} 1$ rats were compared to sham subgroup (Table 4).
Effect of oil mixes (G2 and G3 groups) on reepithelization of skin lesions in rats compared to sham subgroups

Values were significantly different on day $7 \quad(\mathrm{p}<0.01)$ comparing stimulated vs. Sham groups. No significant differences occurred on Day 14 and Day 21 timepoints (Table 5).

TABLE 4 - Effect of saline (G1) or oil mixes (G2 and G3 groups) on exudate of skin lesions of rats comparing Stimulated to Sham subgroups.

\begin{tabular}{ccccccc}
\hline TP & \multicolumn{2}{c}{ G1 } & \multicolumn{2}{c}{ G2 } & \multicolumn{2}{c}{ G3 } \\
\hline & SHAM & EE & SHAM & EE & SHAM & EE \\
\hline $7^{\mathrm{TH}}$ DAY & $2(1-2)$ & $3(2-3)^{*}$ & $1.5(1-2)$ & $2(1-3)$ & $2(1-3)$ & $2(1-3)$ \\
$14^{\mathrm{TH}}$ DAY & $1.5(1-3)$ & $2(1-3)$ & $1(1-2)$ & $2(1-2)$ & $1(1-2)$ & $1(1-2)$ \\
$21^{\mathrm{TH}}$ DAY & $1(1-2)$ & $2(1-3)$ & $1(1-1)$ & $2(1-3)$ & $1.5(1-3)$ & $2(1-3)$ \\
\hline
\end{tabular}

TP = Time-point. Group G1, Negative Control (Saline);group G2, Neutral control ( $\omega-3+\omega-6+\omega-9)$; group G3, test $(\omega-6+\omega-9)$,. non-stimulated (Sham) and stimulated (EE) groups. The data represent Median+range (minimum-maximum) of microscopic scores. Tissue samples were collected on $7^{\text {th }}, 14^{\text {th }}$ and $21^{\text {th }}$ days after injury. Kruskal-Wallis/Dunn tests. $* \mathrm{p}<0.05$ compared to Sham

TABLE 5 - Effect of saline (G1) or oil mixes (G2 and G3 groups) on re-epithelization of skin lesions of rats comparing Stimulated to Sham subgroups.

\begin{tabular}{|c|c|c|c|c|c|c|}
\hline \multirow[t]{2}{*}{$\mathrm{TP}$} & \multicolumn{2}{|c|}{ G1 } & \multicolumn{2}{|c|}{ G2 } & \multicolumn{2}{|c|}{ G3 } \\
\hline & SHAM & $\mathrm{EE}$ & SHAM & $\mathrm{EE}$ & SHAM & $\mathrm{EE}$ \\
\hline $7^{\mathrm{TH}} \mathrm{DAY}$ & $2(1-2)$ & $0(0-1) * *$ & $2(1-2)$ & $2(0-2)$ & $2(0-2)$ & $2(0-2)$ \\
\hline $14^{\mathrm{TH}} \mathrm{DAY}$ & $2(0-2)$ & $2(2-2)$ & $1(0-2)$ & $2(2-2)$ & $2(1-2)$ & $2(2-2)$ \\
\hline $21^{\mathrm{TH}} \mathrm{DAY}$ & $2(2-2)$ & $0(0-1)$ & $1(0-2)$ & $1(0-2)$ & $1,5(0-2)$ & $1,5(0-2)$ \\
\hline
\end{tabular}

Effect of oil mixes (G2 and G3 groups) on HSP27, nuclear transcription factor kappa $b(N F-k B)$ and nitrotyrosine (NT) immunohistochemical results on the seventh day, in non-stimulated rats compared to negative control

HSP27 and NT expression levels were not significant different on the 7th day. However, NF-kB expression levels were significantly greater $(\mathrm{p}<0.05)$ in $\mathrm{G} 2$ rats compared to $\mathrm{G} 1$ at the same timepoint (Table 6).
TABLE 6 - Heat shock protein 27 (HSP27), nuclear transcription factor kappa $\mathrm{b}(\mathrm{NF}-\mathrm{kB})$ and nitrotyrosine (NT) immunohistochemical results on the seventh day, in non-stimulated rats treated with saline (G1) or oil mixes (G2 and G3 groups).

\begin{tabular}{lccc}
\hline & G1 & G2 & G3 \\
\hline HSP27 & $88.80 \pm 7.01$ & $76.60 \pm 13.55$ & $73.00 \pm 17.12$ \\
NF-kB & $23.50(17-61)$ & $87.50(23-198)^{*}$ & $72.00(14-110)$ \\
NT & $77.50 \pm 15.21$ & $76.20 \pm 14.43$ & $87.70 \pm 16.08$ \\
\hline
\end{tabular}

G1 = Negative Control -Saline, G2 = Neutral control, $\omega-3+\omega-6+\omega-9$, G3=test, $\omega-6+\omega-9$., non- stimulated groups. The data represent Mean values $( \pm$ standard deviation) or median (range) of cells count from three specific markers on immunohistochemistry. ANOVA/Bonferroni or Kruskal-Wallis/Dunn tests as required. $* \mathrm{p}<0.05$ compared with G1. 


\section{Histopathology}

Figure 2 depicts histology findings of all groups.
Immunohistochemistry showed positive staining for epithelial cells (black arrows) in stimulated G-3 rats, identified by the intense brown coloration (Figure 2).
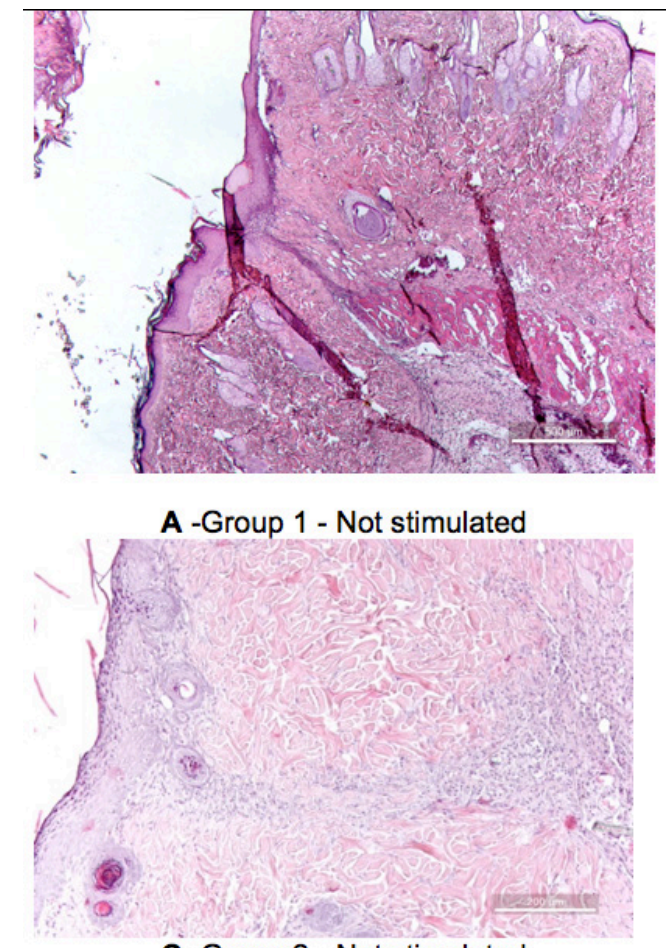

C -Group 2 - Not stimulated

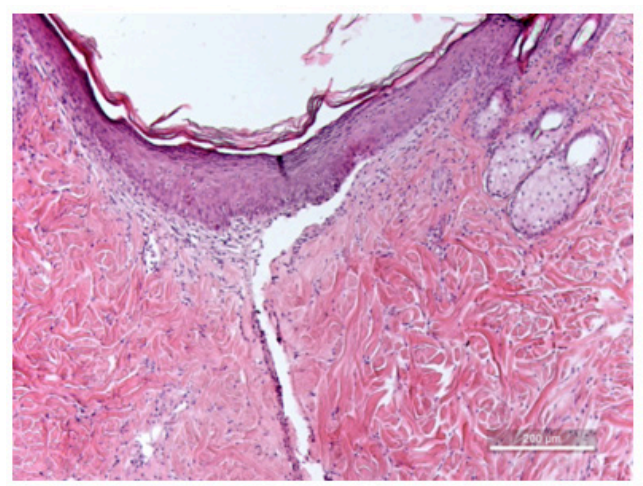

E Group 3 - Not stimulated
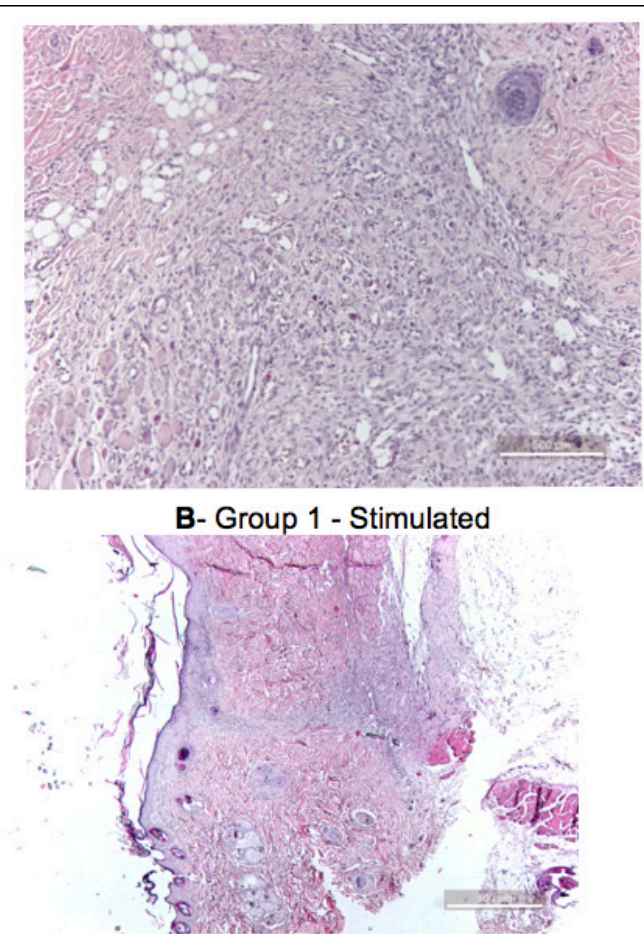

D- Group 2 - Stimulated

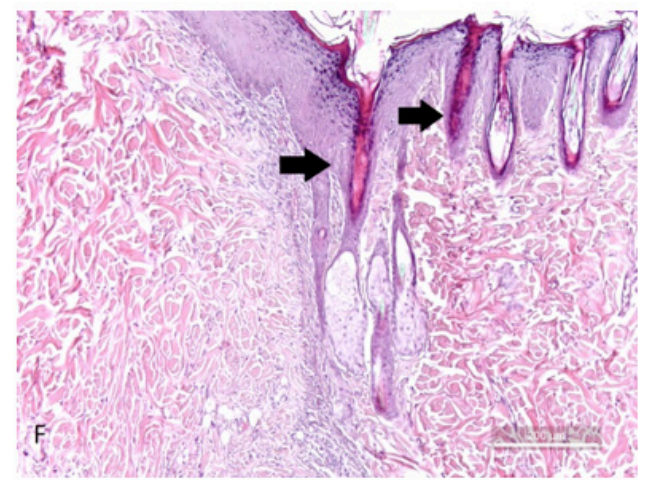

F Group 3 - Stimulated

FIGURE 2 - Histological section of rat skin from non-stimulated (A) and stimulated saline groups (B); corn+soybean oils non-stimulated (C) and stimulated (D) groups; olive+canola+flaxseed oils non-stimulated (E) and stimulated (F) groups (x300).

Notes: $\mathrm{A}=$ Mono and polymorphonuclear cells, total reepithelializarion, moderate fibrosis; $\mathrm{B}=$ Mononuclear cells, total reepithelialization, mild vascularization; $\mathrm{C}=$ Mononuclear cells, total reepithelialization, mild vascularization; $\mathrm{D}=$ Exsudates, mononuclear cells, partial reepithelialization, moderate fibrosis; $\mathrm{E}=$ Mononuclear cells, partial reepithelialization, moderate fibrosis, no vascularization; $\mathrm{F}=$ Mononuclear cells, total reepithelialization, moderate fibrosis,. stained epithelial cells (black arrows).

\section{Discussion}

The relationship between endogenous electrical activity and wound healing has been investigated in several areas of clinical practice and has been well documented ${ }^{15-17}$. M i c r o c u r r e n t electrical neuromuscular stimulation (MENS), applied for treating ulcers by venous impairment accelerates the healing process ${ }^{18}$. A previous study ${ }^{16}$ demonstrated an increase of ATP generation in the skin of rats subjected to MENS, which makes evident the increase of protein synthesis, as well as the increment of transportation by plasma membrane. Considering that ATP is a key factor within the healing process besides being the main energy source of the cell, a higher arrival of ATP is demanded to control primary functions of damaged cells, such as the vital minerals (sodium, potassium, magnesium, 
calcium) transportation towards inside and outside the cell ${ }^{19}$. A recent study investigated the effect of microcurrent stimulation $(10 \mu \mathrm{A})$ on wound healing in rats. The results have demonstrated that the treatment is effective in promoting tissue repair besides exerting positive effects on the newly formed tissue area, number of fibroblasts, number of newly formed vessels, and epithelial thickness 2 .

Prior administration of nutraceutical blends for seven, 14 and 21 days before the surgical incision characterizes nutritional preconditioning. In our experiments, blends of oils containing polyunsaturated fatty acids were used: a mixture with nutraceutical potential with ALA (canola+flaxseed+olive oils) and an isolipidic mixture without nutraceutical potential (corn+soybean oils), was used as a neutral control.

Tissue repair was studied in the different groups by comparing inflammatory and proliferative processes and tissue reorganization. For this purpose, samples were collected from the wound area seven, fourteen and 21 days after experimentally induced injury. Temporal differences in tissue repair were observed between the different treatments.

In the present study, the administration of oil mixes before surgery without associated electric stimulation had no beneficial effects on the healing (exsudates and epithelialization (Table 2) of wounds on the 14 and 21 th day timepoints. However, significant effects were observed on the 7th day timepoint demonstrating a positive effect of the oil mixes. On the other hand the absence of significant differences between oil+microcurrent stimulation groups and control group (saline) concerning exudate and epithelialization variables opposes the result found in another study where the application of Jatropha curcas L. seed oil alone was not effective on experimental wound healing when compared to control, but microcurrent application alone or combined with the oil exerted significant differences in the parameters studied. The use of $\omega-6+\omega--9$ oils (corn+soybean oils) promoted a significant decrease in vascularization on the 7 th post-operative day and decreased fibrosis on 14 th day (Table 3 ). When $\omega-3+\omega-$ $6+\omega--9$ mix (olive+canola+flaxseed oils) was used the same effects were observed at day 7 only. Therefore, when a single dose of corn+soybean oils is given, these effects last up to the 14th day.

Tissue expression of nitrotyrosine and HSP27 showed no statistical difference when comparing groups and timepoints. The results demonstrate that preconditioning with oil mixes as well as microcurrents do not promote and increase in nitrotyrosine and HSP27 expressions in the skin of rats in this experimental model. However the increase in NF-kB expression $(p<0.05)$ in $G 2$ rats compared to G1 on the 7th day. shows the beneficial effect of corn+soybean oil mix during the first phase of the healing process.

\section{Conclusion}

Preconditioning with microcurrents has proinflammatory effects while oil mixes 1 and 2 decrease fibrosis and vascularization in the proliferative phase of cicatrization, whereas preconditioning with microcurrents or mono and polyunsaturated oils induces no alterations in scar repair.

\section{References}

1. Agarwal PK, Singh A, Gaurav K, Goel S, Khanna HD, Goel RK. Evaluation of wound healing activity of extracts of plantain banana (Musa sapientum var. paradisiaca) in rats. Indian J Exp Biol. 2009 Jan;47(1):32-40. PMID: 19317349.

2. Mendonça FA, Passarini Junior JR, Esquisatto MA, Mendonça JS, Franchini CC, Santos GM. Effects of the application of Aloe vera (L.) and microcurrent on the healing of wounds surgically induced in Wistar rats. Acta Cir Bras. 2009 Mar-Apr;24(2):150-5. PMID: 19377785.

3. Sen R, Baltimore D. Multiple nuclear factors interact with the immunoglobulin enhancer sequences. Cell. 1986 Aug 29;46(5):70516. PMID: 3091258.

4. Siebenlist U. NF kappa B/I kappa B proteins. Their role in cell growth, differentiation and development. Madrid, Spain, July 7-10, 1996. Biochim Biophys Acta. 1997 Feb 22;1332(1):R7-13 PMID: 9061013.

5. Landry J, Huot J. Modulation of actin dynamics during stress and physiological stimulation by a signaling pathway involving p38 MAP kinase and heat-shock protein 27. Biochem Cell Biol. 1995 Sep-Oct;73(9-10):703-7. PMID: 8714691.

6. Okamoto CT. HSP27 and signaling to the actin cytoskeleton focus on "HSP27 expression regulates CCK-induced changes of the actin cytoskeleton in CHO-CCK-A cells". Am J Physiol. 1999 Dec;277(6 Pt 1):C1029-31 PMID: 10600753.

7. Beckmann JS, Ye YZ, Anderson PG, Chen J, Accavitti MA, Tarpey MM, White CR. Extensive nitration of protein tyrosines in human atherosclerosis detected by immunohistochemistry. Biol Chem Hoppe Seyler. 1994 Feb;375(2):81-8. PMID: 8192861.

8. Levonen AL, Patel RP, Brookes P, Go YM, Jo H, Parthasarathy S, Anderson PG, Darley-Usmar VM. Mechanisms of cell signaling by nitric oxide and peroxynitrite: from mitochondria to MAP kinases. Antioxid Redox Signal. 2001 Apr;3(2):215-29. PMID: 11396477.

9. Padmaja S, Huie RE. The reaction of nitric oxide with organic peroxyl radicals. Biochem Biophys Res Commun. 1993 Sep 15;195(2):539-44. PMID: 8373394.

10. Calder PC. Immunoregulatory and anti-inflammatory effects of n-3 polyunsaturated fatty acids. Braz J Med Biol Res. 1998 Abr;31(4):467-90.

11. Calder PC. Fatty acids and gene expression related to inflammation. Nestle Nutr Workshop Ser Clin Perform Programme. 2002;7:19-36. PMID: 12481693.

12. Santos VNS, Ferreira LM, Horibe EK, Duarte IS. Electric microcurrent in the restoration of the skin undergone a trichloroacetic acid peeling in rats. Acta Cir. Bras. 2004;19(5):466-70. doi: 10.1590/ S0102-86502004000500003.

13. Borba GC. Estimulação elétrica pré-incisional na cicatrização em pele de rato (Dissertação). Universidade Federal de São Paulo; 2009.

14. Gál P, Vidinský B, Toporcer T, Mokrý M, Mozes S, Longauer F, Sabo J. Histological assessment of the effect of laser irradiation on skin 
wound healing in rats. Photomed Laser Surg. 2006 Aug;24(4):4808. PMID: 16942428.

15. Watson T. Current concepts in electrotherapy. Haemophilia. 2002 May;8(3):413-8. PMID: 12010443.

16. de G de Gaspi FO, Foglio MA, de Carvalho JE, Santos GM, Testa M, Passarini JR Jr, de Moraes CP, Esquisatto MA, Mendonça JS, Mendonça FA. Effects of the topical application of hydroalcoholic leaf extract of oncidium flexuosum sims (Orchidaceae) and microcurrent on the healing of wounds surgically induced in Wistar rats. Evid Based Complement Alternat Med. 2011;2011:950347. doi: 10.1155/2011/950347.

17. Castro FC, Magre A, Cherpinski R, Zelante PM, Neves LM, Esquisatto MA, Mendonça FA, Santos GM. Effects of microcurrent application alone or in combination with topical Hypericum perforatum L. and Arnica montana L. on surgically induced wound healing in Wistar rats. Homeopathy. 2012 Jul;101(3):147-53. doi: 10.1016/j.homp.2012.05.006.

18. Assimacopoulos $\mathrm{D}$. Wound healing promotion by the use of negative electric current. Am Surg. 1968 Jun;34(6):423-31. PMID: 5651495.

19. Cheng N, Van Hoof H, Bockx E, Hoogmartens MJ, Mulier JC, De Dijcker FJ, Sansen WM, De LoeckerW. The effects of electric currents on ATP generation, protein synthesis, and membrane transport of rat skin. Clin Orthop Relat Res. 1982 Nov-Dec;(171):264-72. PMID: 7140077.

\section{Acknowledgements}

To Mr. Osvaldo Fedell, Managing Director of HTMElectronics (Amparo-SP, Brazil), who provided the Stimulus Face HTM equipment for this study; Mrs. Conceição da Silva Martins laboratory technician and Daniele Feijão de Souza nursing technician for their valuable work during the development of this research.

\section{Correspondence:}

Prof. Dr. Paulo Roberto Leitão de Vasconcelos

Rua Prof. Costa Mendes, 1608/3 andar, Bloco Didático

60430-140 Fortaleza-CE Brasil

Tel.: (55 85)3366-8063

paulolleitao@gmail.com

Received: Oct 15, 2014

Review: Dec 17, 2014

Accepted: Jan 12, 2015

Conflict of interest: none

Financial source: National Council for Scientific and Technological Development (CNPq)

${ }^{1}$ Research performed at Experimental Surgery Laboratory (LABCEX), Department of Surgery, Faculty of Medicine, Federal University of Ceara (UFC), Fortaleza-CE, Brazil. Part of Master degree thesis, Postgraduate Program in Surgery, UFC. Tutor: Prof. Dr. Paulo Roberto Leitão de Vasconcelos. 